\title{
DEMONSTRATIVE CONTENTS AND OPAQUE THOUGHTS. REPLY TO VALENTE ${ }^{1}$
}

\author{
MARIO GÓMEZ-TORRENTE \\ https:/ / orcid.org/0000-0002-5957-6544 \\ Instituto de Investigaciones Filosóficas \\ Universidad Nacional Autónoma de México (UNAM) \\ Mexico City \\ Mexico \\ mariogt@unam.mx
}

\author{
Article info \\ CDD: 121.68

\section{Keywords \\ Demonstratives \\ Transparency \\ Content}

Received: 01.10.2020; Accepted: 17.10.2020

https://doi.org/10.1590/0100-6045.2020.V43N4.MV

\begin{abstract}
Matheus Valente presents a number of examples designed to show that my theory of reference fixing for demonstratives violates the desideratum that demonstrative thoughts should be transparent to speakers. In this note I argue that the alleged desideratum is not really such and defend my theory against other criticisms made by Valente.
\end{abstract}

Matheus Valente's (2020) contribution focuses on issues surrounding my account of when a referential intention overrides another referential intention that conflicts with the first, in cases when both conflicting intentions are

${ }^{1}$ Support from the research project no. PIDPID-107667GB-I00 of the Spanish Ministry of Science and Innovation is gratefully acknowledged. 
intended by the utterer to fix the referent of a particular use of a demonstrative. In Roads to Reference I propose that there is a key convention to the effect that, in cases of conflicting intentions, when one (and only one) of them is perceptual (i.e. is one in which the intended referent is represented perceptually), this overrides the others when it comes to fixing the reference of a use of a demonstrative (see Gómez-Torrente (2019), 51-2). Note that, as is most often the case with the conventions postulated for the different kinds of expressions in the book, this convention gives only one of the roughly sufficient conditions for the reference of a demonstrative. This means that the account doesn't exclude the possibility that there are cases of conflicting intentions behind a use of a demonstrative that does conventionally refer to some particular object, and yet the intention that conventionally overrides the others is not a perceptual intention. In fact, I tentatively suggest that a convention with implications of this kind may be in operation in some cases (see Gómez-Torrente (2019), 54 n.25; we will come back to this suggested convention below). ${ }^{2}$ The book also postulates the existence of other conventions for demonstrative reference and reference failure that also adopt the form of statements of sufficient conditions. An important feature of the resulting picture of reference fixing for demonstratives is that the set of conventions giving sufficient conditions need not contemplate all situations (all the conditions) when a demonstrative might be used. This has the effect that a

2 Valente says that, according to me, "if the conflict does not involve a perceptual intention, then the verdict is always Neither" (my emphasis), i.e. the verdict is always that the relevant use of a demonstrative neither conventionally refers nor conventionally fails to refer; but this is not my view, as Valente's subsequent discussion itself makes clear! 
respectable number of cases of uses of demonstratives are in all likelihood neither implied to refer by the extant conventions nor implied by them to fail to refer; these will be cases where there will be reference failure, but not conventionally determined reference failure, and hence cases about which a competent user of demonstratives need not know that there is reference failure (even if she is aware of all the contextually relevant facts). My view is that in many cases of conflicting intentions (but not in cases where one (and only one) of the conflicting intentions is perceptual, of course) there will be reference failure of the not-conventionally-determined kind. These include in all likelihood the cases where there are several conflicting perceptual referential intentions involved. ${ }^{3}$

Valente's main worry about this picture is that it makes it very easy for changes in a speaker's perceptual situation

3 A view concerning cases of conflicting intentions in general, that is rarely considered and that I don't consider in the book, is that in such cases the use of the demonstrative conventionally refers to all the objects determined by those intentions. See my reply to Mena in this issue for some reasons why I think this view is (and is widely thought to be) unattractive. Valente attributes this view to Siegel (2002) for cases where the conflicting intentions involved are all perceptual, but I think he misinterprets Siegel. Siegel just says that she is undecided between this view and the view that (when the conflicting intentions involved are perceptual, and perhaps whenever there are conflicting intentions involved) the demonstrative conventionally fails to refer (see in particular p. 12 of Siegel (2002)). As in other cases of indecision on the part of competent speakers considered in Roads to Reference, I take Siegel's indecision to provide support for my view of such cases; perhaps if she had considered the possibility that in some cases a use of a demonstrative neither conventionally refers nor conventionally fails to refer, she would have adopted my view of the cases in question. 
to induce changes in the semantic status of otherwise similar uses of a demonstrative by that speaker. Take my example of the speaker who, while touching a tree and seeing another, intends (perceptually) to refer with a use of "this" in This is a tree with such a nice trunk to the tree he is touching and to the tree he is seeing (which he thinks are the same tree) (see Gómez-Torrente (2019), 42). In my view, this is probably a case where "this" neither conventionally refers nor conventionally fails to refer. But, as Valente notes, if the speaker closes his eyes and can therefore form only the tactile referential intention, a subsequent use of "this" by him will conventionally refer to the touched tree, according to my view-even if the speaker forms also a memorial referential intention to refer to the recently seen tree. But does this fact directly create a problem for my view? Valente doesn't say it does, presumably because he shares with me the intuition that a use of "this" in an utterance of This is a tree with such a nice trunk in the second situation appears to refer to the touched tree. But he thinks that more indirect considerations suggest that my view is wrong.

One such consideration relies on an example where, if my picture is correct, and ultimately as a result of changes in a certain speaker's perceptual situation, the speaker would appear to be led to make what Valente calls a "logical mistake". Here is how Valente describes the example:

There are many bees flying in your visual field. You focus your eyes on a specific male bee and start following it as it slowly paces around; you think 'this is a striped bee'. Since the only referential intention at this stage is a perceptual visual link to one bee, you successfully refer to it. But then the bee picks 
up some speed and, as it crosses the path of another one, you unknowingly start following the other female bee. Taking it to be the same as before, you think 'this is a female bee'. Now you're in a Perceptual (visual)/ Memorial ("the same bee as I was tracking before") case. Still, perception always trumps memory, and you successfully refer to the female bee.

No intuitively apparent problem for my view thus far, I suppose, and in particular no intuitively apparent problem for the predictions my picture makes concerning the semantics of the utterances involved in the example. But that there must be a problem, according to Valente, comes out if we attend to something the speaker may be tempted to do:

You then make an existential generalization on the basis of your two thoughts: 'there exists a female striped bee'. This reasoning does not seem to be invalid or logically blameworthy-still, if we follow GómezTorrente's view on demonstrative referencefixing, it will be "formalizable" as an existential generalization on the basis of premises about distinct referents. You have thus committed a logical mistake (more specifically, you've made an existential generalization of the form $\exists x(F x \& G x)$ on the basis of premises whose form is $a$ is $F$ and $b$ is $G$ ).

Why is this a problem? According to Valente, it is undesirable to accuse a competent speaker of making 
"logical mistakes". Now by this he doesn't mean mistakes consisting in applying logically incorrect rules of inference (something that does seem to be undesirable), but mistakes consisting in "having traded on the identity of premises with distinct references". The alleged undesirability of accusing a speaker of doing this makes him favor a view, that he also attributes to Recanati, according to which cases of conflicting intentions all lead to reference failure and, in the case at hand, to the fact that "the subject has merely failed to see that one of the premises did not refer to anything (still a mistake, but not a "logical" one)".

To be perfectly honest, I just don't see in what sense the alleged mistake of failing to see that the second "that" (unlike the first "that") lacks a referent is less "logical" (and less serious, I guess, on Valente's view) than the mistake of failing to see that it has a referent different from the one that the first "that" had. I have a strong intuition that the utterance of the second "that" has the female bee as referent (and I don't think Valente really has a different intuition, as I said). From this it follows that Valente's speaker simply commits a fallacy of equivocation without realizing it (hardly a rare phenomenon), and I really doubt that anything more is needed to think that this is the correct diagnosis of the example. But can anything more be said to reinforce the intuition in view of Valente's uneasiness?

Perhaps something can be said after we realize what the general conclusion is that Valente is aiming at with his indirect considerations. This conclusion is that, "according to [Gómez-Torrente's] view, demonstrative thought is not transparent", something that he takes to be obviously undesirable. What is transparency, and why should a failure of transparency of demonstrative thought be undesirable? Valente says that "the contents of our utterances (the thoughts they express) are not transparent to us" when "their identity or distinctness is not apriori assessable". He also 
says that my view of demonstrative reference "opens the way for the possibility that, not only the identity of the things we refer to (which everybody agrees is not apriori assessable), but also the sameness and distinctness of our own thoughts themselves is opaque to us", this being the feature of the view that Valente takes to be clearly undesirable.

Well, it's inevitable to retort, first, that if my view implies that Valente's speaker's thoughts about bees are opaque to her, Valente's view doesn't make them less opaque. For recall that on his view that speaker must think that the thought behind her second utterance is completely different from what it in fact is as well- she must think of it as a complete thought about a certain bee, while on Valente's view it is in fact (presumably) an incomplete thought about nothing in particular. Perhaps realizing this may make Valente less uneasy about views sympathetic to the non-transparency of demonstrative thought.

But second, I think that a non-transparency view is clearly the natural view of demonstrative thought, as shown by consideration of what I suppose are even less controversial examples. Recall, the opaqueness of demonstrative thought simply means that one cannot always tell a priori whether two demonstrative linguistic utterances one makes have the same content. Now think of a Greek contemporary of Homer, one fine evening, pointing to Venus and uttering That is a planet (or rather the Greek equivalent), and then think of the same person, one fine morning, pointing to Venus and uttering That is a planet. On the natural, probably most extended theory of demonstrative content (which, in fact, is the theory that Valente presupposes in his examples), the two utterances have the same (demonstrative) content, as "that" refers 
(directly) to the same object in both (the planet Venus). ${ }^{4}$ But certainly it's also the natural view of the ancient Greek's situation that he cannot correctly tell a priori whether his two demonstrative utterances have the same content. Or think of Rebekah pointing to Esau and telling an acquaintance This is Esau, and a day later pointing to Esau's twin brother and saying to another acquaintance This is Esau. On the natural theory of demonstrative content the two utterances have different contents, as "this" refers to Esau in the first and to Jacob in the second. But certainly it's also the natural view of Rebekah's situation that she cannot correctly tell a priori whether her two demonstrative utterances have different contents. I doubt more can be said to appease Valente's uneasiness here.

Another worry of Valente has to do with an example I give where I propose that a certain descriptive intention overrides another. As he describes the example, it

\footnotetext{
${ }^{4}$ As stressed in Roads to Reference (see p. 20), the big picture there is actually broadly compatible with a view of demonstrative semantic content on which, say, the content (the real referent!) of a demonstrative utterance is a certain descriptive property. On a view of this kind, demonstrative contents would presumably be transparent in Valente's sense. However, as also noted in the book, we would still need a theory of when a particular thing is conventionally talked about in paradigmatic uses of demonstratives. The question of what makes some particular thing the thing conventionally talked about with a use of a demonstrative is the ultimately interesting question in Roads to Reference. But this said, I will also say that my own tentative view of demonstrative semantic content is the standard Kaplanian direct reference view (Valente's view) on which paradigmatic successful utterances of "that", say, refer (directly) to the particular objects that they are conventionally used to talk about.
} 
involves a subject that, after thinking about several possible courses of action, says 'That's what I have to do!' both with the intention of referring to the event of donating money to his friend John's organization, and of referring to the event of donating money to the most effective charity NGO in town. As it happens, his friend John's organization is actually a fraudulent scheme, so the subject mistakenly believes that the two descriptive intentions point to the same action when they do not. Still, Gómez-Torrente argues, and I concur, that the demonstrative 'that' seems to successfully refer to his donating money to his friend's organization (and not to the NGO that in fact is the most effective in town).

As Valente notes, in the book I am only tentative about what convention might be operating in the example (or about whether there is some other explanation for the impression of successful reference). But I do incline toward the view that some appropriate convention is operating and yielding the intuitive verdict, a convention that must thus imply that a certain kind of descriptive referential intention would override conflictive descriptive referential intentions not of that kind when it comes to demonstrative reference. The tentative convention in Roads to Reference is that a description that allows the speaker to identify the described object overrides a description that doesn't allow that-and presumably the description "my donating money to my friend John's organization" by itself allows me to identify what I have to do (given the background of my other intentions, beliefs, etc.), while the description "my donating money to the most effective NGO in town" doesn't. 
I disagree with some things Valente says about this issue. First he asks us to consider the following modification of my example:

the subject in the story knows a website that includes a database of the most effective NGOs in town but has no idea of how to contact his friend John, or even what his organization was called. If that was the case, the intention that represents the event by a description that helps prompt identification of the NGO would have been the former, unlike in (what I take to be) Gómez-Torrente's description of the story. Regardless of that, I think demonstrative reference would not change: the subject would still have referred to the event of donating to his friend John's organization.

I have the opposite intuition; I think that if the speaker's mental background is so different from the one in the original story, so that he has a lot of information about the most effective NGO in town, including presumably information about which one it is and how to locate it, but has only a vague idea about John's present life aside from the (wrong) idea that he chairs that NGO, then the reference of his "that" will be his donating money to the NGO that comes out as most effective in the database. It's interesting that there is a divergence of intuitions here; it would be good to see what other informants would think about the modified example.

Valente proposes that the original example ought to be reconstructed as not involving more than one referential intention-the intention of referring to the subject's donating money to his friend John's organization; on 
Valente's reconstruction, to the extent that the description "my donating money to the most effective NGO in town" appears in the subject's mind, it is only in a "collateral belief" identifying this event with the event of his donating money to John's NGO. In the end, Valente relies on this proposal when he makes the suggestion that one ought to be able to diagnose the original example "without having to postulate the existence of special cases where some descriptive referential intentions are qualitatively distinct, and thus trump the others". Valente would like to have a theory on which such alleged trumping simply did not really exist, and where all cases in which it appears to play a role are not really cases of conflicting intentions.

Unfortunately, it seems clear that such a suggestion will not do. For one thing, one can just imagine cases where there are such conflicting referential intentions (and where one intuitively trumps the others). And if there are such cases, one cannot just stipulate them away proposing that they can somehow be reconstructed as cases where there is just one referential intention together with some collateral identifying beliefs. Speakers are free to form the referential intentions they please, and as theorists we have to deal with that, presumably via the postulation of an appropriate convention about when some descriptive referential intentions override others. The convention proposed in Roads to Reference and recalled above, which as I say there is in a way a generalization of the book's convention of Successful demonstrative reference via non-conflictive perceptual referential intentions, is only tentative, though I think it or something in the vicinity must do the job. But this whole issue clearly requires more detailed consideration, which I hope to be able to provide elsewhere. 


\section{REFERENCES}

Gómez-Torrente, M. (2019), Roads to Reference. An Essay on Reference Fixing in Natural Language, Oxford University Press, Oxford.

Siegel, S. (2002), "The Role of Perception in Demonstrative Reference", Philosophers' Imprint 2, no. 1, $<$ www.philosophersimprint.org/002001>.

Valente, M. (2020), "Bifurcations on the Road: Conflicting Intentions and Demonstrative Reference", Manuscrito, this issue.

$(c c)$ BY 